DOI: http://dx.doi.org/10.18764/2358-4319.v10n3p173-194

\title{
Leituras literárias clandestinas no contexto de uma escola técnica capixaba
}

Rosana Carvalho Dias Valtão ${ }^{1}$

\section{RESUMO}

Este artigo é um recorte dos resultados produzidos por meio da pesquisa de mestrado "Práticas e representações de leitura literária no Ifes/Campus de Alegre: uma história com rosto e voz". A pesquisa investigou como a leitura literária acontece nessa escola de ensino técnico, mapeando em qual contexto leitor o grupo social dos alunos dessa instituição está inserido, quais são suas práticas e representações de leitura. Para isso, a investigação dialogou com o trabalho do historiador francês Roger Chartier e os princípios epistemológicos da História Cultural, no que se refere à história do livro, da leitura e da literatura. No desenvolvimento do trabalho, foram realizadas pesquisas bibliográfico-documental e de campo, em perspectiva qualitativa, utilizando o método dedutivo. Considerando o princípio de que toda realidade cultural é construída nas relações existentes entre os grupos sociais, constatou-se a existência de uma prática de leitura que se desvencilha do trabalho com leitura de literatura em sala de aula. Foram identificadas, ainda, as modalidades partilhadas de ler das comunidades de leitores presentes no contexto estudado: percebemos que as principais vias de acesso e as formas de aquisição do objeto cultural (livro de literatura) acontecem por meio de empréstimos e trocas entre os próprios alunos e constatamos que seus pares são os principais mediadores da leitura literária existente nesse espaço. Os resultados presentes neste trabalham nos oportunizam pensar em como intervir no contexto de formação do leitor de literatura em uma escola de ensino médio.

Palavras-chave: Leitura Literária. Ensino Médio. Práticas e Representações.

1 Mestre em Letras. Professora de Língua Portuguesa do Instituto Federal do Espírito Santo (Ifes)/Campus de Alegre. Membro do Grupo de Pesquisa Literatura e Educação - Ufes. E-mail: rosanad@ifes.edu.br 


\title{
Clandestine literary readings in the context of a capixaba technical school
}

\begin{abstract}
This article is a summary of the results produced through the masters research "Practices and representations of literary reading in Ifes / Campus de Alegre: a history with face and voice". The research investigated how the literary reading happens in this technical school, mapping in which reader context the social group of the students of this institution is inserted, what are their practices and representations of reading. To this end, the research was a dialogue with the work of the French historian Roger Chartier and the epistemological principles of Cultural History in the history of books, reading and literature. In the development of the work, bibliographical-documental and field research were carried out, in a qualitative perspective, using the deductive method. Considering the principle that all cultural reality is built in the existing relations between social groups, it was verified the existence of a practice of reading that gets rid of work with reading literature in the classroom. We also identified the shared modalities of reading from the communities of readers present in the context studied: we perceive that the main access routes and the forms of acquisition of the cultural object (literature book) happen through loans and exchanges between the students themselves And we find that their peers are the main mediators of literary reading in this space. The results present in this work allow us to think about how to intervene in the context of the formation of the literary reader in a high school.
\end{abstract}

Keywords: Literary Reading. High school. Practices and Representations.

\section{Lecturas literarias clandestinas en el contexto de una escuela técnica capixaba}

\section{RESUMEN}

Este artículo es un recorte de los resultados producidos por medio de la investigación de maestría "Prácticas y representaciones de lectura literaria en el Ifes / Campus de Alegre: una historia con rostro y voz". La investigación investigó cómo la lectura literaria ocurre en esa escuela de enseñanza técnica, mapeando en qué contexto lector el 
grupo social de los alumnos de esa institución está inserto, cuáles son sus prácticas y representaciones de lectura. Para ello, la investigación dialogó con el trabajo del historiador francés Roger Chartier y los principios epistemológicos de la Historia Cultural, en lo que se refiere a la historia del libro, de la lectura y de la literatura. En el desarrollo del trabajo, se realizaron investigaciones bibliográficas-documental y de campo, en perspectiva cualitativa, utilizando el método deductivo. Considerando el principio de que toda realidad cultural se construye en las relaciones existentes entre los grupos sociales, se constató la existencia de una práctica de lectura que se desprende del trabajo con lectura de literatura en el aula. Se identificaron, además, las modalidades compartidas de lectura de las comunidades de lectores presentes en el contexto estudiado: percibimos que las principales vías de acceso y las formas de adquisición del objeto cultural (libro de literatura) ocurren por medio de préstamos e intercambios entre los propios alumnos y constatamos que sus pares son los principales mediadores de la lectura literaria existente en ese espacio. Los resultados presentes en este trabajo nos permiten pensar en cómo intervenir en el contexto de formación del lector de literatura en una escuela secundaria.

Palabras clave: Lectura Literaria. Enseñanza Media. Prácticas y Representaciones.

\section{Introdução}

A pesquisa Práticas e representações de leitura literária no Ifes/ Campus de Alegre: uma história com rosto e voz foi desenvolvida no contexto do Instituto Federal do Espírito Santo (Ifes)/Campus de Alegre, partindo da premissa de que a escola, principalmente a escola pública, em nossa sociedade, é uma das mais importantes mediadoras da relação entre leitor e leitura literária. Assim, o contexto escolar torna-se um campo fecundo para compreender como a mediação de leituras acontece na formação do sujeito leitor, em nosso caso particular, do aluno do ensino médio. Vemos, a partir de Dalvi (2013, p. 74), que, nessa instância da formação do sujeito - ensino médio -, o estudante jovem está, supostamente, em contato com diferentes campos da literatura: se por um lado a escola lhe dá acesso ao campo "erudito", por outro, a arte literária que corre à margem do cânone o cerca por 
vários mediadores sociais. Essa percepção de que os jovens leem, mas nem sempre leem o que a escola prescreve, se delineou para nós a partir da observação atenta de práticas "subterrâneas"2 de leitura dentro do nosso espaço-tempo de trabalho, ou seja, a prática de leitura permeia o cotidiano escolar, entretanto, parece-nos uma prática que em nada, ou muito pouco, se alia ao trabalho desenvolvido em sala de aula.

Interessou-nos, então, conhecer as práticas de leitura dos estudantes de cursos técnicos integrados ao ensino médio no Campus de Alegre do Ifes, saber que tipos de leitura literária acontecem nessa instituição escolar, bem como conhecer seus principais mediadores. Esta pesquisa se insere em um contexto mais amplo de investigação, os estudos do grupo de pesquisa Literatura e Educação, da Universidade Federal do Espírito Santo (Ufes).

Utilizamos na pesquisa de campo as técnicas de aplicação de questionário, realização de entrevistas e observação com registro fotográfico, procedimentos realizados com intuito de compreender um pouco melhor as práticas de leitura literária dos alunos do Ifes/Campus de Alegre dos cursos técnicos integrados ao ensino médio.

Devido ao número de alunos matriculados na escola e a carga horária desses estudantes, elegemos os alunos das terceiras séries para participarem da pesquisa; visto que, esses alunos frequentam a escola há três anos, ou seja, as influências da escola sob esse público já estão mais consolidadas. Com isso, buscamos evidências sobre o trabalho de mediação realizado pela instituição na formação desses estudantes enquanto leitores. Nas quatro turmas de terceira série, há 114 alunos matriculados, distribuídos entre os cursos de agropecuária e agroindústria; desse número, 100 alunos participaram da pesquisa, os outros não estavam presentes no início da investigação ou tiveram que realizar outras atividades durante a realização da pesquisa.

Apresentamos, então, um recorte dos dados coletados que nos permitiram identificar quais representações e práticas de leitura literária permeiam o contexto do ensino médio de uma escola do Estado do Espírito Santo.

2 Chamamos de práticas de leitura subterrâneas aquelas que acontecem fora do contexto didático de sala de aula, que, muitas vezes, não são contempladas nos planos de ensino, que rompem com a pedagogia escolar. 


\section{O corpus de investigação}

Nossa pesquisa, com objetivo de compreender o contexto em que se insere a leitura literária de jovens estudantes de cursos técnicos integrados ao ensino médio, em uma época marcada pelo desenvolvimento tecnológico e pela emancipação do mercado do livro, se insere no Campus de Alegre, do Instituto Federal do Espírito Santo (Ifes), uma realidade distinta dos grandes centros urbanos; propondo, deste modo, um rompimento com o etnocentrismo cultural e trazendo a lume a microrrealidade de uma comunidade de leitores com delineamentos sociais bem marcantes.

Os alunos dos cursos técnicos integrados ao ensino médio são 548 estudantes, em 2015, de acordo com a secretaria da escola; a forma de ingresso desses estudantes atende às legislações que regem as regras de vagas em instituições públicas de ensino com ingresso através de processo seletivo; sendo que $37 \%$ dos alunos atualmente matriculados, o que corresponde a mais de duzentos estudantes, ingressaram na instituição por alguma ação afirmativa do governo, garantindo a esses sujeitos estudos em uma escola que, talvez sem essas políticas afirmativas, possivelmente não lhes estaria acessível, haja vista o histórico de caráter altamente seletivo para ingresso nas instituições federais de educação.

Levando em consideração a resposta dada pelos pais ou responsáveis no momento da matrícula e a nós cedida pela secretaria da escola, $84 \%$ dos estudantes declaram morar em zona urbana, enquanto $16 \%$, na zona rural. Todavia, vale ressaltar que municípios como Alegre, Jerônimo Monteiro, Muniz Freire, Ibitirama, Muqui, Guaçuí e lúna - municípios com maior quantidade de alunos na escola - são cidades do interior do estado do Espírito Santo. A maioria não possui livrarias; as bibliotecas públicas, quando existem, contam com pouco investimento econômico e cultural, geralmente, se restringem às bibliotecas escolares, que por sua vez não possuem profissionais formados para exercer a função de bibliotecário. Ou seja, uma zona urbana bem diferente das cidades grandes, com boas bibliotecas, museus com exposições sobre escritores famosos, feiras de livros, livrarias que nos fisgam pelos olhos, enfim, um contexto que, em geral, pensamos ser favorecedor à prática de leitura; Silva (2009, p. 117) destaca que vários estudos sobre o processo de aquisição da leitura têm evidenciado que um ambiente letrado 
se torna fundamental para a formação do leitor; e, de acordo com Paim e Prigol (2009), citados inicialmente, bibliotecas públicas de qualidade, feiras de livros, crítica literária, entre outros, são os principais mediadores da prática leitora.

Outro conhecimento interessante para nossa investigação se dá na renda econômica da família, visto que vivemos em um país em que educação é cara, bons livros têm preço considerável, sem contar o acesso a outras práticas culturais. No grupo investigado, apenas $4 \%$ vivem com três ou mais salários mínimos. Desconsiderando a arbitrariedade dos informantes na declaração dos dados no ato da matrícula, na crença tática de que a omissão dos reais valores da renda familiar os torna mais propícios a receber algum benefício governamental (auxílio transporte, uniforme, entre outros), vemos que $80 \%$ dos alunos vivem com renda bruta menor que 1,5 salários mínimos, o que talvez nos indique também o interesse em fazer parte dessa instituição, que, além de investir em uma educação de qualidade, oferece aos alunos quatro refeições diárias, atendimento médico, transporte, academia, reforço escolar e internato para os alunos de outros municípios.

Por outro lado, ter um público com essa situação econômica atrela à escola maior responsabilidade quanto à oferta, manutenção e seleção dos materiais de leitura e de seu acervo literário para que ela seja capaz de contribuir com formação do aluno-leitor. A pesquisa Retratos da Leitura no Brasil (2011) apresenta um dado que chama a nossa atenção quanto à relação entre renda e prática de leitura: a investigação demonstra que nas classes C e D/E estão 82\% dos considerados não-leitores; retomando Neves (2004, p. 17), a instituição educacional, então, torna-se a principal mediadora da prática de leitura, já que para a maioria dos sujeitos a escola é o lugar onde eles têm o encontro com o livro, já que para alguns não sobra dinheiro para adquiri-los, enquanto, para outros, o dinheiro que sobra a família não utiliza para comprar livros.

Dos alunos investigados, 49\% declaram pertencer ao gênero feminino e $51 \%$ ao masculino, o que confirma a presença das moças em uma instituição incialmente frequentada somente por rapazes. A idade desse grupo, representada no gráfico abaixo, demonstra que a maioria dos alunos está frequentando a escola em idade regular - finalizando o ensino médio com idade entre 16 e 17 anos (89\% dos entrevistados); indiciando, com isso, um baixo número de reprovação/repetição em séries anteriores entre esses alunos. 


\section{As representações e práticas (clandestinas) de leitura na escola de ensino médio}

Por meio da investigação, percebemos que a leitura (tomada de forma generalizada), para $65 \%$ dos entrevistados, está relacionada a prazer, passar o tempo, distrair e divertir, ou seja, a leitura é vista como prática prazerosa, sem finalidade ou com objetivos didáticos, a leitura cursiva, como fruição, privada e pessoal, voltada para as experiências subjetivas e autônomas com a leitura. Vale ressaltar que, entre os que usam a leitura para se divertir, $67 \%$ são do sexo feminino, demonstrando que há ainda um distanciamento dos meninos em relação à leitura.

Sobre a importância da literatura, $91 \%$ dos entrevistados consideram a leitura de literatura como importante para a vida do sujeito e apontam como principais justificativas para suas respostas adquirir conhecimento, melhorar escrita e ampliar vocabulário, o que quer dizer que a visão para leitura literária é uma visão utilitária e desvinculada do prazer; vejamos o gráfico abaixo:

GRÁFICO 1: Finalidade da leitura de literatura

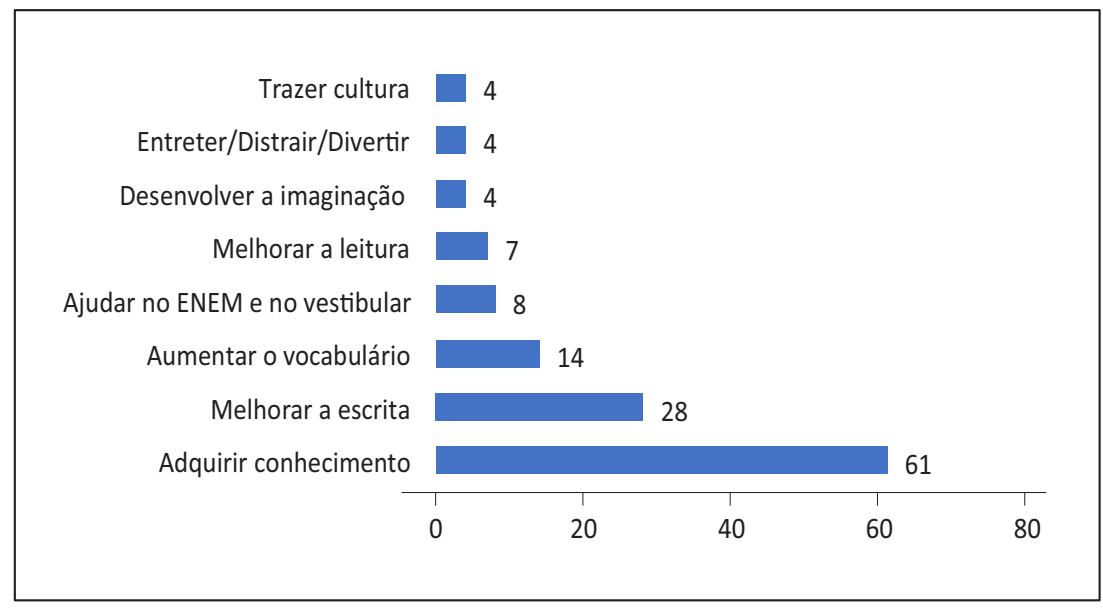

Fonte: Elaborado pela autora

Dados que contradizem os $65 \%$ que afirmam usar a leitura para passar o tempo, distrair, se divertir e ter prazer, como demonstrado anteriormente. Podemos pensar que, ao nos referirmos no questionário sobre leitura de literatura, evocamos nos entrevistados a leitura literária como o ato de ler textos consagrados, textos clássicos, eruditos, uma 
noção pragmática e escolarizada da literatura - bem ao modo da leitura analítica - de maneira diferente, a questão sobre a finalidade de leitura sugere aos entrevistados suas escolhas e preferências frente ao texto a ser lido. Tanto que, quando questionados se a leitura de literatura é uma considerada uma atividade prazerosa, 29\% dos entrevistados responderam que não, $8 \%$ às vezes e $4 \%$ não responderam, ou seja, há um número considerável (41\%) que não alia leitura de literatura e prazer e deleite. Entre as principais justificativas por não considerar a leitura de literatura uma atividade prazerosa estão não gostar de ler, achar cansativo, não ser uma atividade vivida nos dias atuais, não trazer conhecimentos técnicos e possuir linguagem rebuscada.

Detectamos, então, a representação de leitura como funcional, voltada para uma finalidade didática, ou seja, eles leem para adquirir conhecimento, cultura, contribuir com a formação crítica do cidadão, ajudar na formação de opiniões, desenvolver o vocabulário, a fala e a escrita. Em entrevista ${ }^{3}$, a aluna Baleia (informação verbal) afirma que

[...] com a prática da leitura se desenvolve o vocabulário, você aprende vários significados de palavras e outras culturas também, você lê o livro que conta sobre a China, que conta sobre a Índia, que conta sobre os Estados Unidos, então, no meu ponto de vista, com a leitura, ela meio que forma a pessoa, você meio que fica por dentro da cultura, você tem um conhecimento maior, você tem um aprendizado... é uma coisa que você nem percebe, é espontaneamente, você lê e não percebe que você tá adquirindo aquele conhecimento.

Hazel Grace (informação verbal) vê a prática de leitura como uma contribuição para que o sujeito tenha sucesso na vida, "[...] quem tem acesso à leitura vai ter informação de forma diferente [...]".

3 Por se tratar de entrevistas semiestruturadas (ou seja, os entrevistados teriam mais liberdade e flexibilidade para responder, produzindo respostas mais longas e complexas), optamos por gravá-las em áudio e vídeo para facilitar as análises, sendo armazenadas, posteriormente, em arquivos no modelo $\mathrm{mp3}$. Para garantir que as informações pessoais dos alunos fossem respeitadas, seus nomes foram substituídos por pseudônimos, garantindo o máximo sigilo e evitando constrangimentos durante e após a realização da pesquisa. Para a transcrição das entrevistas, optamos por fazê-la registrando o que nos convinha para as futuras análises, por isso, desconsideramos falas desconexas com os objetivos da pesquisa, brincadeiras, entre outros. O registro foi realizado respeitando a fala de cada entrevistado, grafando de acordo com a verbalização de cada um; em casos extremos, optamos por fazer as mínimas correções gramaticais necessárias, já que o conteúdo que nos interessava não sofreria nenhuma alteração. 
Sofia (informação verbal), que incialmente deixou claro que a leitura servia para ajudar na memorização, rompe com a representação utilitária da prática de leitura, ao afirmar que começou a ler porque ficava muito sozinha em casa; relatando o crescimento do gosto pela leitura a partir do momento que começou a ler para passar o tempo ocioso. Essa representação da prática de leitura é acompanhada por Gus (informação verbal) "quando eu leio um livro eu busco mais entretenimento do que aprendizagem [...]"; por Capitu (informação verbal) que esclarece que ler "[...] é muito bom para passar o tempo [...]", e por Rita, quando diz que "[...] [ler] é tudo que a gente gosta [...]".

Os investigados demonstraram fazer parte de um contexto leitor, seja pela presença de livros em casa e nas escolas, seja por visitar bibliotecas, livrarias ou feiras de livros, mesmo que esporadicamente.

As representações de leitura para esses alunos se dá como prática prazerosa e de deleite; entretanto, toda leitura tida como obrigatória - ação muito descrita pelos entrevistados - ou atividade escolar se torna tediosa, maçante, fastidiosa e desestimulante, o que faz surgir certa aversão às obras literárias que povoam o cenário escolar, os clássicos da literatura, principalmente a brasileira. Percebemos na fala da maioria dos entrevistados uma repulsa em relação às obras indicadas pela escola, principalmente a literatura nacional, confirmando o que vimos em Petrucci: "[...] as práticas de leitura abertamente consumistas, que em nome de uma absoluta liberdade de leitura recusam todo sistema de valores e toda atitude pedagógica, são cada vez mais extensas" (PETRUCCl, 1999, p. 217).

Entre os alunos investigados e considerados não leitores, a prática de leitura no ensino fundamental acontecia somente quando era obrigada, e, em casa, com a família, embora houvesse incentivo dos pais, havia poucos modelos de leitores de literatura a serem seguidos; afirmam ter em casa exemplos de leitores de jornal, revistas e bíblia. Percebemos que os sujeitos se apropriaram das práticas sociais das comunidades com as quais conviviam e convivem, eles constroem suas representações, o que gera suas práticas, uma grande cadeia: as práticas sociais de grupo vão gerar novas práticas por parte dos sujeitos que fazem parte dele, como demonstrou Chartier (1990, p. 27-28). Ressaltando, dessa maneira, que o incentivo à prática de leitura desde cedo pode contribuir com a instituição de jovens leitores, principalmente de literatura.

Sobre a prática de leitura de literatura, quase $60 \%$ dos alunos investigados leem sempre ou às vezes, demonstrando que, mesmo imer- 
sos em uma formação técnica, com oito diárias de estudo, há leitores de literatura - 22\% apontam os tipos/categorias de textos literários como os textos que mais leem, independente se para distrair ou adquirir conhecimento.

O principal suporte para leitura entre esses jovens é o digital (46\%), $17 \%$ dos entrevistados usam tanto o digital quanto o impresso, o que revela o acesso deles às tecnologias, inclusive na hora de terem acesso aos livros de literatura que leem - $2 \%$ dos alunos baixam seus livros de literatura da internet, como veremos no gráfico a seguir.

GRÁFICO 2: Principais meios de acesso aos livros de literatura dos alunos investigados

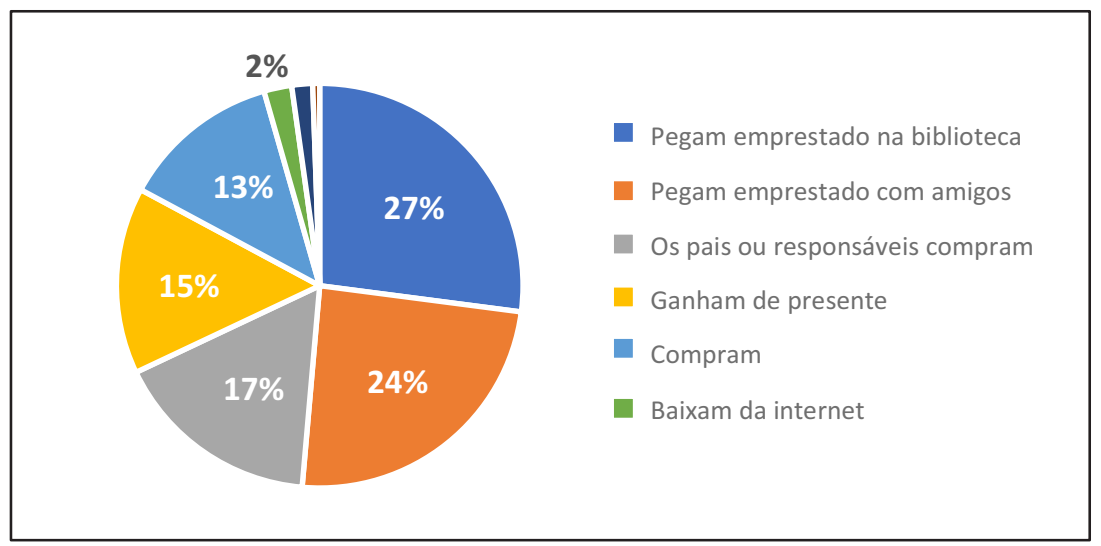

Fonte: Elaborado pela autora

Entre esses alunos, 47\% adquirem de alguma forma as obras lidas, enquanto $51 \%$ não possuem os livros que leem, eles pegam o livro lido emprestado em bibliotecas ou com amigos. Temos, com isso, uma cadeia de empréstimos dentro da instituição o que se relaciona com a ausência do comércio do livro (livrais e feiras) na região e com a situação econômica mais baixa das famílias; e reitera a necessidade de a escola investir em um acervo literário de qualidade. Esses dados, também, demonstram a necessidade de investimento por parte da instituição de ensino em práticas mediadoras capazes de alcançar esses leitores, já que, mesmo alguns alunos buscando livros nas bibliotecas, inclusive a da escola investigada, o maior mediador das escolhas e das leituras dentro dessa comunidade de leitores são seus pares, seus colegas de escola. Cinquenta e nove alunos afirmaram que suas leituras são incentivadas e 
influenciadas por pessoas que também lhes emprestam a obra a ser lida, ou seja, não basta simplesmente dizer que é necessário ler, que determinado livro é bom, é necessário proporcionar acesso a ele.

Quando questionados sobre os livros de literatura que estão lendo ou a última obra lida, dez alunos responderam que não se lembravam, catorze não responderam à pergunta, entretanto 138 livros apareceram nas respostas dos alunos.

Tabela 6: Ranking das últimas obras de literatura lidas pelos alunos investigados

\begin{tabular}{|l|c|c|}
\hline \multicolumn{1}{|c|}{ Obra } & $\begin{array}{c}\text { Número de alunos } \\
\text { que leram }\end{array}$ & ACERVO DA BIBLIOTECA \\
\hline A culpa é das estrelas & 6 & SIM \\
\hline Divergente & 5 & NÃO \\
\hline Harry Potter & 5 & SIM \\
\hline Ela disse, ele disse & 4 & NÃO \\
\hline O pequeno príncipe & 4 & SIM \\
\hline Se eu ficar & 4 & NÃO \\
\hline O menino do pijama listrado & 4 & SIM \\
\hline O corcel negro & 4 & SIM \\
\hline Não se apega, não & 4 & NÃO \\
\hline Convergente & 4 & NÃO \\
\hline
\end{tabular}

Fonte: Elaborado pela autora

A fotografia $1^{4}$, coletada em espaço externo da escola, já permitiu-nos identificar a obra lida - Jogos vorazes. O flagrante nos remete para prática de leitura individual, sem um interlocutor para leitura; mesmo tento alguém ao seu lado, a leitura é solitária e particular.

Constatamos a existência de uma prática de leitura bem marcante entre os investigados, uma prática formada basicamente pelos livros que fazem parte das listas dos mais vendidos publicadas por sites e revistas especializadas. São obras de grande apelo comercial, produções que caracterizam e expandem o mercado do livro, são os famosos best-sellers, representantes de uma importação de produtos da indústria

4 A fotografia foi coletada por meio da técnica de observação sistemática, em que não há envolvimento do observador com os participantes da pesquisa (MOREIRA; CALLEF, 2008, p. 195). 
cultural $^{5}$. Nessa lista, identificamos obras que sofrem os efeitos da motivação gerada junto ao público consumidor pelas empresas que produzem cultura.

Fotografia 1: Aluna lendo Jogos vorazes durante intervalo do almoço

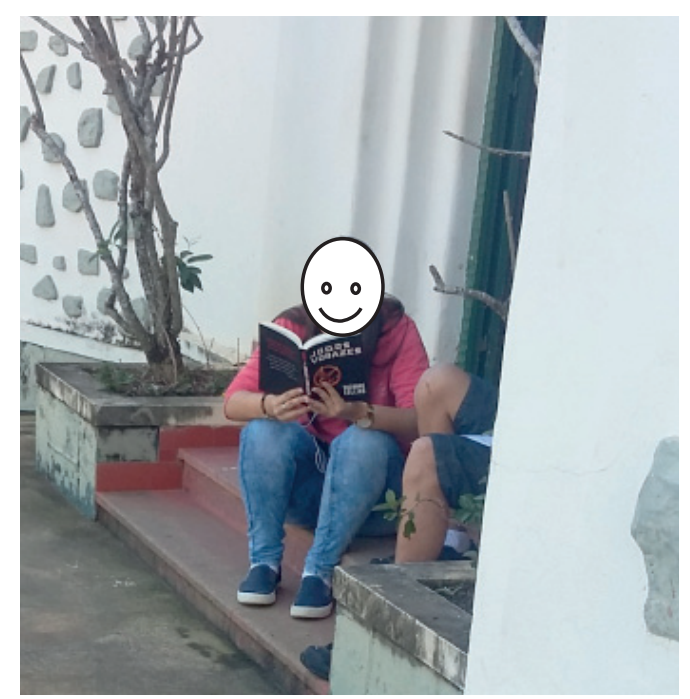

Fonte: Da autora

Vemos que as leituras dos alunos investigados rompem com toda legitimidade do cânone escolar. São essas mesmas obras que aparecem na lista das indicações (e por que não mediação?) dos alunos investigados e na de leituras feitas por indicação. Ou seja, a prática de leitura dos sujeitos investigados é resultado do trabalho de mediação entre os próprios alunos, reafirmando as práticas comuns entre os membros dessa comunidade de leitores, e refletem, ainda, uma investida muito maior e poderosa da indústria cultural na formação do gosto leitor.

Contrastando com essas obras, os livros de literatura que os investigados menos gostaram são os livros denominados romances clássicos

5 Não temos a pretensão e nem tempo hábil para estendermos nossas discussões sobre as vertentes da indústria cultural; entretanto, não podemos negligenciar que a prática de leitura desse grupo está atrelada ao mercado do livro, em que o livro de literatura é tomado como produto capaz de dar lucro aos produtores e, ainda, como origem de diversos subprodutos que, de certa forma, contribuem para seu sucesso e, automaticamente, para sua venda. Melo (1999) deixa claro que o aparecimento de novas leituras e releituras de livros de literatura (seja filme, telenovelas, seriados ou mesmo os mais recentes meios de divulgação dessas obras como os vlogs e booktubers) servem de meio para ampliar o consumo desses bens. 
brasileiros e os livros indicados por professores, fazendo saltar aos olhos um afastamento entre as leituras espontâneas e as leituras ditas escolares.

Interessante perceber que, para 16\% dos investigados, não há um livro que eles menos tenham gostado, o que nos leva para duas possibilidades: todas as obras lidas agradaram ou não leram nenhum livro; corroborando com esse dado, $14 \%$ dos entrevistados afirmaram não lembrar da obra de que menos gostaram. Entretanto, 13\% não respondeu à questão, tendendo a confirmar a inexistência de práticas de leitura literária.

Como toda prática é fruto de representações (CHARTIER, 1990), há entre os jovens pesquisados duas práticas de leitura existentes (considerando a indicação da escola como uma prática de leitura, mesmo alguns afirmando que não leem tais obras): uma indicada pela escola constituída pelo cânone literário - e outra autônoma, marcada por um repertório de mistério, ficção científica, ação, histórias de amor, enfim, leituras denominadas por eles mesmos como best-seller; denominada por Chartier (1998, p. 104) como leituras selvagens, e por Petrucci (1999, p. 217) como "lixo".

Vale ressaltar que as práticas de leituras desenvolvidas pela escola, de acordo com os entrevistados, não incentivam à leitura, são voltadas para apresentação de trabalho, para ganhar nota, para preencher fichas, fazer resumos, o que torna a leitura tediosa e realizada somente quando são obrigados; Melo (1999) afirma que

o leitor formado obrigatoriamente a partir das tarefas escolares deixa de ser leitor quando abandona a escola. [...] Porque esse leitor formado pela escola adquire a sensação de que leitura é algo vinculado à rotina da aprendizagem; portanto, uma atividade chata, cansativa, desinteressante" (p. 71).

Quando questionados se hoje leem mais ou menos que no ensino fundamental, a maioria respondeu que lê menos, e, quando questionados se gostam de ler, afirmam não ter muito tempo para isso e, ainda, apresentam as justificativas para o fato de lerem menos:

Hazel Grace: Eu acho que é porque a gente assim assumiu outras responsabilidades e prioridades que... por exemplo, no primeiro e no segundo ano eu acho que a gente tinha mais projeto assim com leitura, tipo o professor falava olha pra fazer esse trabalho você vai ter que ler esse livro. Eu acho que esse ano, isso 
diminuiu muito... e até porque também tem essa questão do tempo, é muito difícil você fazer a leitura de livro sem que você tem que estudar pra vestibular e outras coisas.

Sra Waters: [...] tem o tempo também, agora eu estudo em tempo integral, então chega em casa a gente já está praticamente morto, então ... e tem outras coisas para fazer, estudar pro vestibular também... aí... Sinhá Vitória: [...] por a gente estudar o dia todo, é uma leitura cansativa, então, às vezes, acaba ficando, a gente, fica cansativo, fica .... a gente fica sem coragem pra poder ler...

A escola de tempo integral com sua carga horária elevada de estudos tem sido fator determinante para afastamento de alguns alunos dos livros de literatura. Sem contar que o investimento da escola/ biblioteca no acervo de literatura é baixo, não há renovação constante; demonstrando certa prioridade para os livros técnicos. Ou seja, mesmo com a falta de tempo e de condições materiais favoráveis (espaço escolar e acervo de interesse continuamente renovado), há leitores na escola, há uma prática de leitura recorrente entre os alunos.

A comunidade de leitores investigada reconhece que os livros lidos apresentam algo em comum que delineia suas práticas: vocabulário mais simples, histórias intrigantes que se relacionam com o universo adolescente-juvenil em que eles estão inseridos, leitura mais fácil, capas chamativas, o que Chartier denomina como "objetos escritos de fraca legitimidade cultural" (CHARTIER, 1998, p. 104). Encontramos entre esses sujeitos a leitura cursiva, feita de forma autônoma e pessoal, calcada no fenômeno de identificação entre objeto escrito e leitor.

Por outro lado, há, entre os investigados, embora um número bem modesto, a prática de leitura dos livros e autores clássicos da literatura brasileira, alguns nomes são apontados como lidos por eles, Carlos Drummond de Andrade, Capitães da areia (Jorge Amado), Vidas secas e Infância (Graciliano Ramos), Dom Casmurro (Machado de Assis), Um certo capitão Rodrigo (Érico Veríssimo) e Lucíola (José de Alencar). Contudo, somente o último foi sugerido pela escola, os outros foram lidos por iniciativa própria, com intuito de ajudar no vestibular e Enem, ou por incentivo de algum parente.

Quando se trata de obras indicadas ou sugeridas pelos professores, dois professores se destacam: o de história e o de geografia. Eles são 
apontados por alguns entrevistados como sendo os que mais indicam obras para leitura, sem contar que essa indicação para dois alunos foi a mediação para suas práticas de leitura atuais.

De outra forma, percebemos determinada repulsa no que se refere aos livros de literatura indicados pelos professores, especificamente os professores de português; afirmam categoricamente não lerem esses livros, mesmo os considerados leitores assíduos. Deixam claro que o que mais os afasta desse campo literário está relacionado aos protocolos de leitura de tais obras (linguagem difícil e truncada, dificuldade de compreensão, histórias que não se relacionam veridicamente com o contexto histórico, entre outros) e à situação de leitura (leitura obrigatória para apresentar trabalho e conseguir ponto, leitura realizada no suporte digital, já que a biblioteca não possui esses livros no acervo e os preços dessas obras, geralmente são mais elevados que o das obras consideradas best-seller ${ }^{6}$ ).

E, reconhecendo a necessidade das obras canônicas em sua formação enquanto leitores e sujeitos sociais, afirmam serem leituras necessárias, mas deixam claro que a ausência de um trabalho de mediação eficaz os afasta desses textos (vale refletir sobre a existência mesmo do gosto por essas obras ou se esse é uma reprodução do discurso escolar sobre a questão).

Percebemos na comunidade de leitores investigada um paradoxo no que se refere à leitura de literatura: os alunos, em sua maioria, leem, entretanto uma leitura diferente do que a escola gostaria que fosse lido; eles recusam com veemência as obras indicadas pelos professores - são contundentes em referir-se aos clássicos literários -, em contrapartida, questionam a ausência de um trabalho mais expressivo de indicação de leituras, de mediação para o ato de ler, já que consideram atividades importantes para sua formação.

\section{Considerações Finais}

O interesse em investigar a comunidade de leitores do Ifes/Campus de Alegre surgiu a partir do confronto entre o discurso sobre a mor-

6 De acordo com Petrucci (1999, p. 213-214), o leitor-consumidor, imerso na grande indústria editorial e no mercado do livro, "deixa-se seduzir ora pelo preço reduzido, ora pela apresentação gráfica, ora pelo interesse do momento e pelo bombardeio publicitário"; ficando exposto a um "fenômeno de leitura generalizada de massa com características de consumo induzido". 
te da leitura entre os jovens do século XXI e a observação das práticas de leitura de estudantes de cursos técnicos integrados ao ensino médio no contexto de sala de aula. Víamos, com isso, um paradoxo entre a representação desses sujeitos no senso comum e suas práticas no cotidiano escolar. Por outro lado, também percebíamos, durante o trabalho docente, certo embate em relação à leitura da literatura disseminada pela escola. Havia, então, a necessidade de entender o que estava acontecendo e como poderíamos intervir nessa realidade.

Para conhecer as práticas, representações e apropriações de leitura de literatura desses sujeitos, investimos em uma pesquisa de campo, com perspectiva qualitativa; utilizamos, então, três técnicas que nos permitiram alcançar nossos objetivos: aplicação de questionário, realização de entrevistas e observação com registro fotográfico.

A representação de leitura dessa comunidade de interpretação hesita entre uma percepção utilitária e funcional, em que a leitura é vista como fonte para adquirir conhecimento, melhorar a escrita, o vocabulário e a interpretação; e outra voltada para o entretenimento, são os leitores que veem a leitura como forma de diversão e prazer usada para passar o tempo.

A pesquisa de campo trouxe a lume as práticas de leitura dos alunos investigados, todas as técnicas aplicadas na pesquisa de campo constataram a existência de leitores na instituição. O questionário nos revelou que $57 \%$ dos jovens estudantes do Ifes/Campus de Alegre leem, sempre e às vezes, livros de literatura, ou seja, mais da metade desses sujeitos têm contato direto com o objeto cultural sobre o qual ajustamos nosso foco; nas entrevistas, com exceção dos alunos considerados não leitores, 39\% de acordo com as respostas dos questionários, todos os entrevistados revelaram estar lendo ou ter lido um livro nos últimos meses; durante a observação ficou claro a circulação de livros na escola e a prática de leitura ficou registrada através de fotografias; dados que contradizem qualquer discurso que negue a existência de jovens leitores na sociedade contemporânea, época marcada pelo bombardeio da produção de bens culturais, em especial, o livro de literatura.

Entretanto, um dado preocupante e que nos chamou muito atenção foi a colocação de muitos alunos, considerados leitores e mediadores de leitura que fazem parte dessa comunidade, sobre estarem lendo menos neste ano da investigação; e, quando perguntamos pelas causas dessa redução, a maior justificativa foi a sobrecarga de estudos, a 
carga horária de oito horas semanais em sala de aula, a necessidade de ter que estudar depois da aula (à noite) para provas, vestibular e Enem; enfim, ficou claro que o ritmo de estudos pouco contribui para prática de leitura desses alunos.

Constatamos, ainda, em nossa pesquisa, que, mesmo a escola possuindo uma biblioteca de qualidade, não há um trabalho eficiente de divulgação e circulação de suas obras, ações que contribuam com a difusão dos livros entre os leitores e não leitores que favoreçam a instituição de uma comunidade de leitores.

Vimos que as leituras dos alunos investigados ultrapassam as fronteiras das práticas escolares; é uma prática cultural que se constrói à margem do cânone, uma leitura marginal, com toda força da palavra. As obras lidas pelos alunos investigados (especificadamente, pelos considerados leitores) são obras de grande apelo comercial, com objetivos mercadológicos, pertencentes à indústria cultural dos best-sellers. Essas obras estão imersas em práticas individuais de leitura, subjetivas, descompromissadas, para prazer imediato, para suprir seu desejo de evasão; é o que Barthes e Compagnon (1987, p. 185-186) caracterizam como comportamento do homem moderno em relação à leitura.

Uma leitura que atende ao gosto imediato desse leitor, que desencadeia um processo de identificação com os elementos e os temas da realidade representada na narrativa, o que gera grande prazer; com esse movimento de identificação, o aluno lê o que gosta e nada além disso. As obras que leem os confrontam com grandes questões existenciais que marcam sua transitoriedade da vida infantil para vida adulta, questões às quais esses leitores estão expostos regularmente, tais como amor, morte, sofrimento, desejo, descoberta de si, sexualidade, entre outras; o aluno se identifica no personagem. Assim como as telenovelas enredavam os telespectadores, confortando suas frustrações, dando significado a seus desejos, assim a leitura literária tem cumprido esse papel.

As leituras dessa comunidade de leitores nos chamam atenção para outra questão: os livros lidos são obras voltadas para a proficiência dos alunos - apresentam linguagem fácil, vocabulário simples, enredos menos complexos, são intrigantes e oferecem leitura rápida; toda leitura que foge a essa regra é vista com aversão, resultando, com isso, em distanciamento dos alunos de obras mais densas, que exijam maior atenção e conhecimento linguístico e em afastamento dos textos mais complexos por não serem capazes de compreendê-los. Isso nos revela 
práticas de leitura abertamente consumistas, que em nome de uma absoluta liberdade de leitura recusam todo sistema de valores e toda atitude pedagógica, e são cada vez mais extensas, como nos alertou Petrucci (1999, p. 217)

As obras preferidas pelos sujeitos estudados fazem parte das listas dos mais vendidos, publicadas por sites e revistas especializadas. São obras de grande apelo comercial, produções que caracterizam e expandem o mercado do livro, são os famosos best-sellers, representantes de uma importação de produtos da indústria cultural. Leituras que rompem com toda legitimidade do cânone escolar. São essas mesmas obras que aparecem na lista das indicações (e por que não mediação?) dos alunos investigados e na de leituras feitas por indicação.

Já no tocante às obras do contexto escolar - as indicações dos professores -, 79\% dos investigados responderam que leem livros a pedido de seus professores; quatro alunos mencionam ter lido ou estarem lendo obras de Érico Veríssimo, Graciliano Ramos, Jorge Amado, Machado de Assis e Carlos Drummond de Andrade; sem contar os dois alunos que estão lendo obras indicadas pelo professor de história. O que demonstra a existência de duas práticas de leitura: uma indicada pela escola - constituída pelo cânone literário -, e outra autônoma, marcada por um repertório de mistério, ficção científica, ação, histórias de amor, enfim, os best-sellers.

Não temos o interesse de (des)qualificar quaisquer leituras, não propomos a valorização ou desvalorização de nenhum campo literário, não nos interessamos em promover o embate entre leitura de best-seller e leitura canônica, indústria cultural e produção erudita. Não referendamos a ideia de total passividade e vitimização dos jovens estudantes do século XXI em suas escolhas literárias, nem negligenciamos o fator de agrupamento desses leitores em comunidades de interpretação que prescrevem práticas e compartilham representações. Contudo, não podemos deixar passar despercebida a maneira como a leitura tipicamente escolar é apropriada pelos alunos; para eles essas leituras são desinteressantes, chatas, com linguagem difícil e fazem parte dos livros lidos que menos gostaram de ler. Precisamos mencionar, ainda, que o trabalho realizado na escola com a leitura das obras ditas clássicas não proporciona também uma apropriação diferente desse campo por eles; a leitura da literatura clássica na escola está atrelada a práticas de leituras voltadas para apresentação de trabalho, para ganhar nota, para preencher 
fichas, fazer resumos, o que não aproxima esses leitores dessas obras e nem corrobora com o incentivo à leitura. Vemos, então, que o contexto escolar didatiza a leitura de literatura, não oferece condições para que o aluno se emancipe enquanto leitor e saia da leitura mercadológica com a qual ele é bombardeado todos os dias.

Por isso, fazemos a defesa de uma atividade mediadora de qualidade pela escola no processo de constituição do sujeito leitor, que se justifica por acreditarmos no papel social das instituições de ensino: a escolarização como inserção plena nas práticas de leitura e escrita, principalmente, torna-se fator fundamental de ingresso e participação na sociedade, e a leitura (como a defendemos aqui) como instrumento de inserção e participação social.

Entendemos, com isso, que o trabalho com leitura precisa oportunizar uma relação produtiva de interlocução entre aluno-leitor e patrimônio cultural - a obra escrita - e ela possa servir de base para os sujeitos pensarem as relações consigo mesmos, com os outros e com o mundo; práticas de leitura que ampliem as tradicionais práticas escolares, em uma pedagogia da leitura que proporcione o acesso (em todos os sentidos) ao objeto cultural, práticas que franqueiam e não engessem a ação de ler.

Então, a partir desses dados, ressaltamos a necessidade de um trabalho de mediação que emancipe e instrua o leitor para a leitura de livros mais densos, de mais difícil conhecimento, um trabalho que, além de sugerir obras, entregar o livro pra o aluno, capacite, faça a leitura fluir, promova a transformação do texto dado a ler em o texto do leitor e favoreça sua apropriação. Precisamos investir em tempo com a leitura literária - e por que não? -, investir nos alunos considerados mediadores de leitura, pois eles são os maiores responsáveis pela circulação de obras literárias na escola; as obras mais lidas foram também as mais sugeridas, são os amigos e colegas de sala de aula que foram apontados como os principais referenciais de leitores; realizando, com isso, o que Vigotski denominava atividade mediatizante (FRIEDRICH, 2012, p. 64), os alunos leitores podem contribuir com o trabalho de mediação da escola, interferindo na prática de seus pares.

Vemos a necessidade de, além de oferecer livros, trazer as leituras dos alunos para sala de aula, "é preciso utilizar aquilo que a norma escolar rejeita como suporte para dar acesso à leitura na sua plenitude, isto é, ao encontro de textos densos e mais capazes de transformar 
a visão de mundo, as maneiras de sentir e pensar" (CHARTIER, 1998, p. 104), é necessário "[buscar] nessas manifestações [cultura de massa, leitura dos alunos] seus pontos de contato com a dita alta literatura, a fim de mais construir pontes que erguer muros" (DALVI, 2013, p. 75), ou seja, um trabalho de emancipação desses sujeitos enquanto leitores, já que constatamos a existência de uma comunidade de leitores ali. E uma boa forma de começarmos com ela é buscarmos pesquisas que investiguem os objetos culturais que correm à margem do campo erudito e fazem parte da prática de leitura desses jovens.

Podemos, então, ao final dessa pesquisa, preconizar algumas intervenções no trabalho realizado pela escola com leitura de literatura para a formação de leitores:

a) levar textos literários na íntegra para sala de aula: ler com os alunos, ler para os alunos, ler sem necessidade de ser atividade avaliativa, ler textos clássicos, mas permitir que os alunos também escolham textos para serem lidos em sala de aula. Precisamos pensar em uma prática de leitura na escola que proporcione, nesse momento de formação e emancipação do leitor, o equilíbrio entre trabalho e lazer, como nos sugeriu Melo (1999); investindo, dessa maneira, no tempo para leitura dentro da própria escola, favorecer o encontro dos alunos com outros textos literários com os quais eles não convivem;

b) proporcionar a apropriação de ferramentas de leitura: explicar técnicas de escrita, recursos literários, diferenças entre gêneros. Oportunizando, com isso, a possibilidade de entendimento de obras literárias mais densas;

c) permitir que as leituras dos alunos frequentem as salas de aula: dar oportunidade para os alunos falarem sobre seus gostos literários (criação de blogs literários, de canais de leitura, de varal de resenhas, de cardápio de leitura, rodas de leitura, clubes de leitura, entre outros), buscar pontos de contato entre as leituras dos alunos e as leituras do cânone escolar (por que não trabalhar paralelamente com as obras $O$ menino do pijama listrado e Capitães da areia? Ou mesmo A culpa é das estrelas e Cinco minutos? Ou O pequeno príncipe e Macunaíma?).

Enfim, chegamos ao final desta investigação não com a sensação do dever cumprido, mas com a certeza de que podemos fazer muito mais, podemos ir mais além. Temos consciência de que conhecer as práticas de leitura dos jovens estudantes dos cursos técnicos integrados ao ensino médio do Ifes/Campus de Alegre servirá para pensarmos no 
árduo processo de, não mais formação, mas de emancipação de leitores; articulando suas práticas com políticas dentro da escola que agreguem valores para leitura considerada clássica, ampliando, e por que não meIhorando, dessa maneira, o trabalho realizado em sala de aula com a literatura.

\section{Referências}

BALEIA; FABIANO; SINHÁ VITÓRIA. Entrevista I. [out. 2015]. Entrevistador: Rosana Carvalho Dias Valtão. Alegre/ES, 2015. 1 arquivo .mp3 (39:14 min.).

BARTHES, Roland; COMPAGNON, Antoine. Leitura. In: ROMANO, Ruggiero (Dir.). Enciclopédia Einaudi: oral-escrito argumentação. Lisboa: Imprensa Nacional Casa da Moeda, 1987. Vol.11, p. 184-206.

BENTINHO; CAPITU; RITA; SOFIA; VIRGÍLIA. Entrevista II. [out. 2015]. Entrevistador: Rosana Carvalho Dias Valtão. Alegre/ES, 2015. 1 arquivo .mp3 (46:02 min.).

CHARTIER, Roger. A História Cultural entre práticas e representações. Tradução Maria Manoela Galhardo. Rio de Janeiro: Bertrand Brasil, 1990.

.A aventura do livro: do leitor ao navegador:conversações com Jean Lebrun/ Roger Chartier. São Paulo: Unesp, 1998.

. Leituras e leitores "populares" da Renascença ao Período Clássico. In: CAVALLO, Guglielmo; CHARTIER, Roger (Org.). História da leitura no mundo ocidental. São Paulo: Ática, 1999, 2 v, p. 117-134.

.A história ou a leitura do tempo. Tradução Cristina Antunes. Belo Horizonte: Autêntica, 2010.

DALVI, Maria Amélia. Literatura na escola: propostas didáticometodológicas. In: DALVI, Maria Amélia, JOVER-FALEIROS, Rita, REZENDE, Neide Luzia de. Leitura Literária na Escola. São Paulo: Parábola, 2013.

FAILLA, Zoara (Org.).Retratos da leitura no Brasil 3. São Paulo: Imprensa Oficial do Estado de São Paulo: Instituto Pró-Livro, 2011.

FRIEDRICH, Janette. Lev Vigotski: mediação, aprendizagem e desenvolvimento: uma leitura filosófica e epistemológica. Campinas/SP: Mercado das letras, 2012. 
GRACE, Hazel; VAN, Peter; GUS; ISAAC; KAITLYN; SRA LANCASTER; SRA WATERS. Entrevista III. [out. 2015]. Entrevistador: Rosana Carvalho Dias Valtão. Alegre/ES, 2015. 1 arquivo .mp3 (42:58 min.).

MELO, José Marques. Os meios de comunicação de massa e o hábito de leitura. In: BARZOTTO, Valdir Heitor (Org.). Estado de leitura. São Paulo: Mercado de Letras, 1999. p. 31-45.

MOREIRA, Herivelto. CALEFFE, Luiz Gonzaga. Metodologia da pesquisa para o professor pesquisador. 2. ed. Rio de Janeiro: Lamparina, 2008.

PAIM, Elison Antonio, PRIGOL, Valdir. Mediação e Formação De Leitores. In: Congresso De Leitura Do Brasil, 17, 2009, Campinas. Anais do $17^{\circ}$ COLE, Campinas, SP: ALB, 2009. Disponível em: <http://www.alb. com.br/portal.html>. Acesso em: 5 set. 2014.

PETRUCCI, Armando. Ler por ler: um futuro para a leitura. In: CAVALO \& CHARTIER, Guglielmo e Roger. (org.) História da leitura no mundo ocidental. Vol. 2. São Paulo: Ática, 1999, p.203-227.

SILVA, Márcia Cabral. Uma história da formação do leitor no Brasil. Rio de Janeiro: EDUERJ; 2009,

Recebido em julho/2017

Aceito em setembro /2017 